\title{
Crystallization kinetics of poly(lactic acid)-talc composites
}

\author{
D. Battegazzore, S. Bocchini*, A. Frache \\ Politecnico di Torino, Alessandria Site, V.le Teresa Michel 5, 15100 Alessandria, Italy \\ Received 18 February 2011; accepted in revised form 5 April 2011
}

\begin{abstract}
The crystallization kinetics of poly(lactic acid) / talc composites were determined over a range of 0 to $15 \mathrm{wt} \%$ of talc. Talc was found to change the crystallization kinetics. The presence of talc increases the crystallization rate and this increase is related to talc concentration and to crystallization temperature. In order to understand the effect of talc and PLA crystallinity on mechanical properties, dynamic mechanical thermal analyses were performed on poly(lactic acid) / talc composites before and after an annealing process. It was demonstrated that the presence of crystals improves thermomechanical properties but in order to achieve good results at high temperatures the reinforcing effect of a filler such as talc is necessary.
\end{abstract}

Keywords: thermal properties, crystallization, polylactic acid, mechanical properties, polymer composites

\section{Introduction}

Poly(lactic acid) (PLA) is a commercially available compostable biobased material that could become a material of choice, due to its high strength and moderate barrier properties. It is a highly transparent and rigid material with a relatively low crystallization rate that makes it a promising candidate for the fabrication of biaxially oriented films, thermoformed containers and stretch-blown bottles [1,2]. Unfortunately the range of application of PLA is severely limited because of low glass transition temperature (around $55-60^{\circ} \mathrm{C}$ ) thus research was focused on the study of PLA crystallization kinetics [3]. At temperature higher than glass transition only the PLA crystalline phase can confer useful mechanical properties. Increasing the crystallization speed of PLA is thus desired [4].

Lactic acid is optically active and thus it has a $\mathrm{L}$ or $\mathrm{D}$ form. The maximum attainable crystallinity level is obtained by minimizing the amount of the other lactide and mesolactide in the lactide used as the major monomer. The crystallinity and crystallization rate of PLA decrease as the purity decreases.
The crystallization half-time was found to increase by roughly $40 \%$ for every $1 \mathrm{wt} \%$ increase in the mesolactide content of the polymerization mixture [5]. However even at high L-LA content PLA crystallization is typically too slow to develop significant crystallinity unless it is induced by strain such as in processes used to produce bottles. In processes such as injection molding where the orientation is limited and the cooling rate is high it is much more difficult to develop significant crystallinity and thus formulation or process changes are required. Researchers have studied the crystallization behaviour [6-9] of PLA; especially the crystallization kinetics $[5,10,11]$; the isothermal melting mechanism [12]; the effects of undercooling and the molecular weight on its morphology and crystal growth [13]; the effects of annealing on the thermal properties, morphology, and mechanical properties of PLA films [14]; and the effects of thermal treatment on compression-molded PLA at different molecular weights [15]. In order to increase crystallinity three main routes can be considered. The first one is to add a nucleating agent that will lower

\footnotetext{
${ }^{*}$ Corresponding author, e-mail: sergio.bocchini@polito.it
} (c) BME-PT 
the surface free energy barrier towards nucleation and thus initiates crystallization at higher temperature upon cooling. A second possibility is to add a plasticizer which will increase the polymer chain mobility and will enhance the crystallization rate by reducing the energy required during crystallization for the chain folding process. The third possibility is to play with the molding conditions, in particular molding temperature and cooling time.

Several potential nucleating agents have been examined in the literature [3]. Talc is a widely used nucleating agent. It was shown that talc nucleates the crystallization of polymers through an epitaxial mechanism [16]. In the case of PLA, it is shown that the crystallization half-time can be reduced by more than one order of magnitude to less than $1 \mathrm{~min}$ when $1 \%$ talc is added [17]. Similarly, strong increase in nucleation density with addition of talc was found in poly(L-lactide-co-mesolactide) [5].

This paper investigated the effect of microtalc concentration on the crystalline content developed during heating-cooling-heating cycle and in isothermal condition. The crystalline content and mechanical properties achieved in different conditions are compared using differential scanning calorimetry and dynamic mechanical analysis. This information would be useful to better understand PLA/talc composites and their manufacturing and possible applications.

\section{Experimental}

\subsection{Materials and sample preparation}

Poly(L-lactic acid) 'NatureWorks ${ }^{\circledR}$ PLA Polymer $3051 \mathrm{D}$ ', average molecular weight $160 \mathrm{kDa}$, ratio 96\% L-Lactide to 4\% D-Lactide units was obtained from Natureworks Minneapolis Minnesota (USA). Industrial microtalc masterbatch 'PLA NA BIO L 6951 ' with $30 \%$ of talc content was purchased from Polyone Belgium SA Assesse (Belgium).

All the material was dried at least for 4 hours at $80^{\circ} \mathrm{C}$ under vacuum to a Karl-Fischer titration moisture content below $500 \mathrm{ppm}$ before processing.

The compounds were melt blended using a co-rotating twin screw micro extruder DSM Xplore $15 \mathrm{ml}$ Microcompounder. Residence time was fixed for all the runs at 5 minutes. To prevent the degradation of the polymers, $\mathrm{N}_{2}$ purge flow was used during the processing. The screw speed was fixed at $60 \mathrm{rpm}$ for the feeding and $100 \mathrm{rpm}$ for the melt mixing.
The heating temperature was set at $180^{\circ} \mathrm{C}$. Percent of talc content is indicated by the number in the sample name (e.g., PLA1T contains $1.0 \mathrm{wt} \%$ talc).

\subsection{Characterizations}

Wide Angle X-Ray Scattering (WAXS) analyses were performed on compression moulded $3 \times 3 \times$ $0.5 \mathrm{~mm}$ specimens with a Thermo ARL diffractometer $\mathrm{X}$-tra 48 using $\mathrm{Cu}-\mathrm{K}_{\alpha} \mathrm{X}$-ray source $(\lambda=$ $1.540562 \AA$ ), step-size $0,02^{\circ}$ at $2{ }^{\circ} \mathrm{C} / \mathrm{min}$ scanning rate.

Scanning Electron Microscope (SEM) pictures were taken with LEO 1400 VP Series (Carl Zeiss, Oberkochen, Germany) on surface of fragile fracture from film samples fractured after cooling by immersion in liquid nitrogen. The samples were metallized with gold.

Differential Scanning Calorimetry (DSC) analyses were performed with DSC Q20 TA Instruments (New Castle, DE, USA) with a double cycle of heating from 0 to $230^{\circ} \mathrm{C}$ at $10^{\circ} \mathrm{C} / \mathrm{min}$ separated by a single cooling cycle at $10^{\circ} \mathrm{C} / \mathrm{min}$ with isothermal step for 3 minutes at 230 and $0^{\circ} \mathrm{C}$. The thermal history of samples was erased by the preliminary heating cycle at $10^{\circ} \mathrm{C} / \mathrm{min}$. The amount of material in the DSC samples was 6-8 mg. An empty pan was used as a reference. The glass transition temperature $\left(T_{\mathrm{g}}\right)$, crystallization temperature $\left(T_{\mathrm{c}}\right)$, cold crystallization temperature $\left(T_{\mathrm{cc}}\right)$, melting temperature $\left(T_{\mathrm{m}}\right)$, crystallization enthalpy $\left(\Delta H_{\mathrm{c}}\right)$, cold crystallization enthalpy $\left(\Delta H_{\mathrm{cc}}\right)$ and melting enthalpy $\left(\Delta H_{\mathrm{m}}\right)$ were determined from cooling and second heating scans. The crystallinity $(\chi)$ of PLA and composites was evaluated using Equation (1):

$$
\chi=\frac{\Delta H}{\Delta H_{\mathrm{m}}^{0} \cdot\left(1-\frac{\% \mathrm{wt} \text { filler }}{100}\right)} \cdot 100
$$

where $\Delta H=\Delta H_{\mathrm{c}}$ (for cooling curves, as $\Delta H_{\mathrm{c}}$ is the specific crystallization enthalpy of the sample) or $\Delta H=\Delta H_{\mathrm{m}}-\Delta H_{\mathrm{cc}}$ (for second heating curves, as $\Delta H_{\mathrm{m}}$ is the specific melting enthalpy of the sample, $\Delta H_{\mathrm{cc}}$ is the specific cold crystallization enthalpy of the sample), $\Delta H_{\mathrm{m}}^{0}$ is the melting enthalpy of the $100 \%$ crystalline polymer matrix $(93.0 \mathrm{~J} / \mathrm{g}$ for PLA $[18,19])$ and $\%$ wt filler is the total weight percentage of talc.

To evaluate isothermal crystallization values, a sample was heated from 25 to $200^{\circ} \mathrm{C}$ at $10 \mathrm{C} / \mathrm{min}$ and 
maintained at $200^{\circ} \mathrm{C}$ for $5 \mathrm{~min}$. Subsequently, it was rapidly cooled $\left(-50^{\circ} \mathrm{C} / \mathrm{min}\right)$ to the isothermal evaluation temperatures of 90, 95, 100, 105 and $110^{\circ} \mathrm{C}\left(T_{\mathrm{i}}\right)$. The sample was held at the isothermal temperature for 120 minutes, allowing crystallization. To observe the melting behavior, the isothermally crystallized samples were reheated to $200^{\circ} \mathrm{C}$ at a rate of $10^{\circ} \mathrm{C} / \mathrm{min}$. The melting temperature that was observed was taken as the maximum of the endothermic transition.

Dynamic Mechanical Thermal Analysis (DMTA) was performed with DMA Q800 TA Intruments (New Castle, DE, USA). The measurements were carried out at a constant frequency of $1 \mathrm{~Hz}$, at a strain amplitude of $15 \mu \mathrm{m}$ with a preload of $0,01 \mathrm{~N}$, a temperature range from 25 to $100^{\circ} \mathrm{C}$ with a heating rate of $3{ }^{\circ} \mathrm{C} / \mathrm{min}$ in tension mode. The samples were prepared by cutting strips from the films with a width of $6 \mathrm{~mm}$, a height of $26 \mathrm{~mm}$ and a thickness of about $0,5 \mathrm{~mm}$ prepared by hot compression molding with $5 \mathrm{MPa}$ at $180^{\circ} \mathrm{C}$ for $3 \mathrm{~min}$. For each material at list three samples were characterized.

\section{Results and discussion}

\subsection{Morphology}

The WAXS spectra of talc is characterized by the presence of three diffraction peaks at $2 \theta=9.5,19.1$ and $28.7^{\circ}$ [20]. The WAXS pattern of PLA is characterized by a broad band with maximum at $2 \theta=$ $16.6^{\circ}$, indicating a completely amorphous structure (Figure 1). Crystalline structure of the polymer matrix is significantly affected by the presence of talc: the composites containing talc show the presence of the three talc peaks and a new peak at $16.6^{\circ}$ due to the crystalline phase of the PLA (inset Figure 1) [21]. Thus, as expected talc enhance PLA crystallization. It is interesting to underline that the

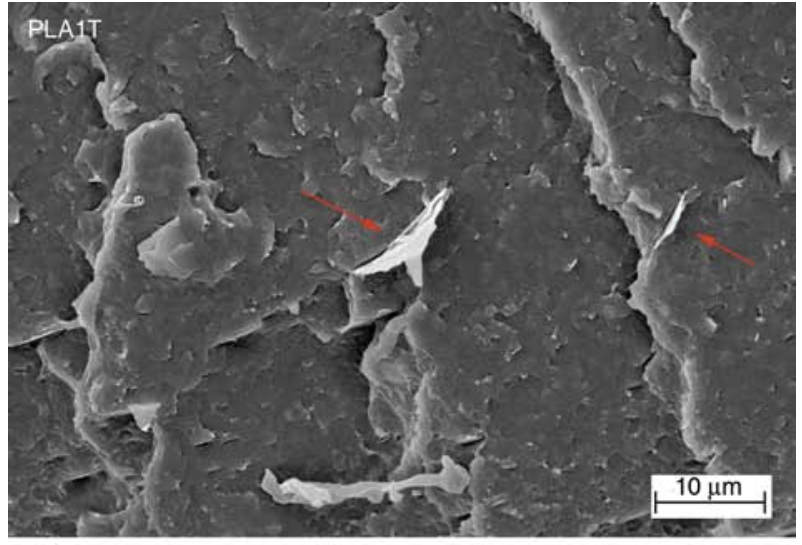

a)

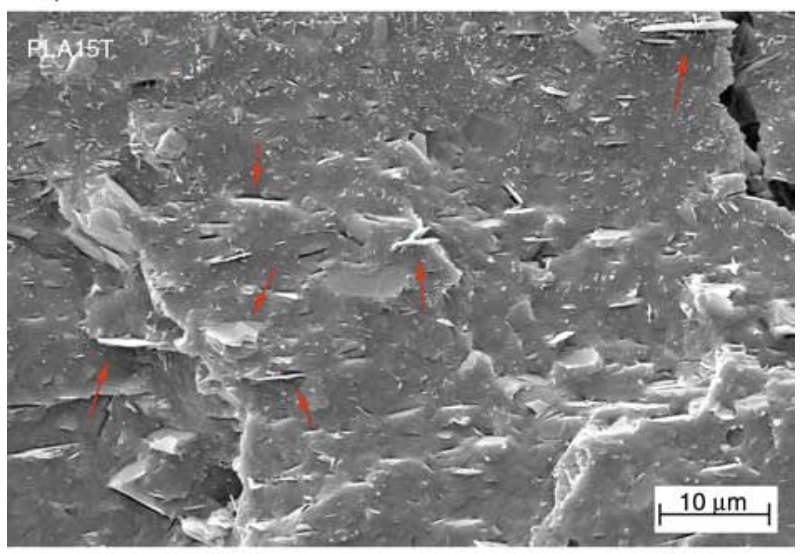

b)

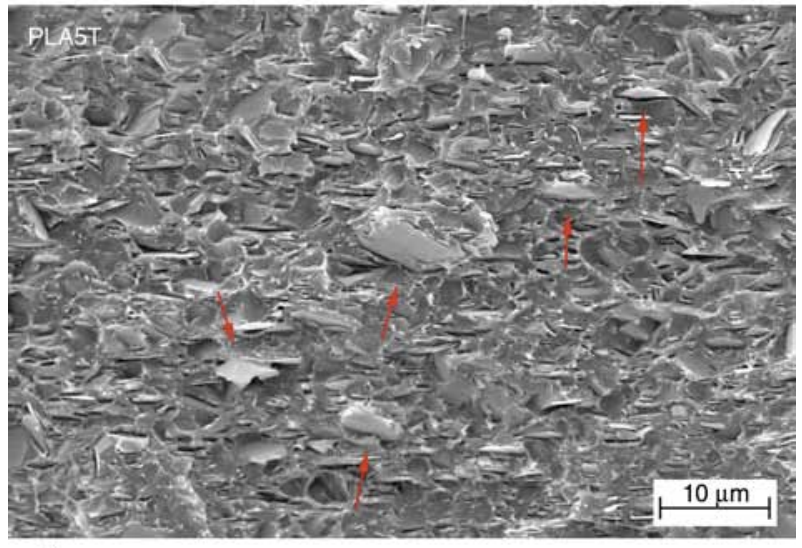

c)

Figure 2. SEM analyses of PLA1T (a), PLA5T (b) and PLA15T (c)

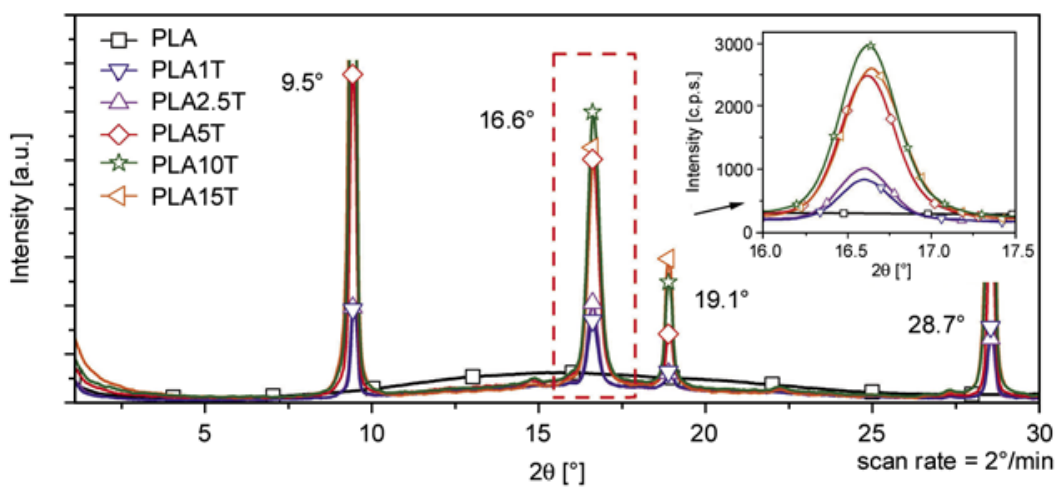

Figure 1. X-ray diffraction of melt-blended samples (inset: magnification of PLA characteristic peak) 
intensities of the three talc peaks seem almost proportional to the talc content.

For the sake of brevity, only SEM analyses of PLA1T, PLA5T and PLA15T are shown because all the composites show a good dispersion. There are no aggregates and the talc lamellae are singularly dispersed. SEM analyses (Figure 2) shows also a wide size distribution of talc lamellae with maximum particle size of about $10 \mu \mathrm{m}$.

\subsection{Thermal analysis}

The thermal history of samples was erased by the preliminary heating cycle. The DSC thermograms recorded during cooling and second heating of PLA composites are reported respectively in Figure $3 \mathrm{a}$ and Figure $3 b$.

The data derived from DSC analyses are reported in Table 1. PLA alone does not crystallize during cooling. Talc induces PLA crystallization on cooling, as already reported [5], the crystallization percentage increases with the concentration of filler.

Neat PLA crystallizes on heating (cold crystallization) with a $T_{\mathrm{cc}}$ of $130^{\circ} \mathrm{C}$ (Figure 3b, Table 1). The exothermic peak of cold crystallization is partially merged with the endothermic melting peak that has a maximum at $152^{\circ} \mathrm{C}$ (Figure $3 \mathrm{~b}$ ). The $\chi_{\mathrm{m}}$ and $\chi_{\mathrm{cc}}$ of PLA have practically the same absolute value and this confirms that crystallization of neat PLA occurs only during heating.

The addition of $1 \mathrm{wt} \%$ of talc (Table 1) leads to a considerable decrease of $T_{\mathrm{cc}},\left(\sim 23^{\circ} \mathrm{C}\right)$, as well as to an increase of total crystallinity respect to neat PLA. The $T_{\mathrm{cc}}$ remains similar for all the samples containing talc. The PLA crystals in PLA/talc composites are formed partially during cooling and partially during cold crystallization. There is an important increase in the crystallinity percentage formed during the cooling cycle from 2.7 to $9.1 \%$ (evaluated as $\chi_{\mathrm{m}}-\chi_{\mathrm{cc}}$ ) with the increase of talc concentration from 1 to $15 \mathrm{wt} \%$. The percentage of crystallization during heating $\left(\chi_{\mathrm{cc}}\right)$, evaluated by heating released by cold crystallization, decreases with the increase of talc concentration. Similarly the overall crystallinity $\left(\chi_{\mathrm{m}}\right)$ decreases with increasing the concentration of talc. Probably this is due to the presence of an higher percentage of crystals formed dur-

Table 1. DSC analysis of PLA, PLA/talc composites

\begin{tabular}{|c|c|c|c|c|c|c|c|c|}
\hline \multicolumn{3}{|c|}{ Sample } & PLA & PLA1T & PLA2.5T & PLA5T & PLA10T & PLA15T \\
\hline \multirow{3}{*}{ Cooling } & $T_{\mathrm{c}}$ & {$\left[{ }^{\circ} \mathrm{C}\right]$} & - & 85 & 86 & 88 & 88 & 89 \\
\hline & $\Delta H_{\mathrm{c}}$ & {$[\mathrm{J} / \mathrm{g}]$} & 0.0 & 0.9 & 2.4 & 2.6 & 4.2 & 4.4 \\
\hline & $\chi_{\mathrm{c}}$ & {$[\%]$} & 0.0 & 0.9 & 2.7 & 2.9 & 5.0 & 5.6 \\
\hline \multirow{8}{*}{$2^{\circ}$ heating } & $T_{\mathrm{g}}$ & {$\left[{ }^{\circ} \mathrm{C}\right]$} & 59 & 57 & 58 & 59 & 60 & 60 \\
\hline & $T_{\mathrm{cc}}$ & {$\left[{ }^{\circ} \mathrm{C}\right]$} & 130 & 107 & 104 & 106 & 103 & 100 \\
\hline & $\Delta H_{\mathrm{c}} \mathrm{c}$ & {$[\mathrm{J} / \mathrm{g}]$} & 12.0 & 26.2 & 24.2 & 19.7 & 16.4 & 13.9 \\
\hline & $\chi_{\mathrm{cc}}$ & {$[\%]$} & 12.9 & 28.5 & 26.7 & 22.3 & 19.6 & 17.6 \\
\hline & $T_{\mathrm{m}}$ & {$\left[{ }^{\circ} \mathrm{C}\right]$} & 152 & $147-153$ & $147-152$ & $147-152$ & $147-152$ & $147-151$ \\
\hline & $\Delta H_{\mathrm{m}}$ & {$[\mathrm{J} / \mathrm{g}]$} & 12.1 & 28.7 & 28.4 & 24.9 & 22.8 & 21.1 \\
\hline & & {$[\%]$} & 13.0 & 31.2 & 31.3 & 28.2 & 27.2 & 26.7 \\
\hline & $\chi_{\mathrm{m}}-\chi_{\mathrm{cc}}$ & {$[\%]$} & 0.1 & 2.7 & 4.6 & 5.9 & 7.6 & 9.1 \\
\hline
\end{tabular}
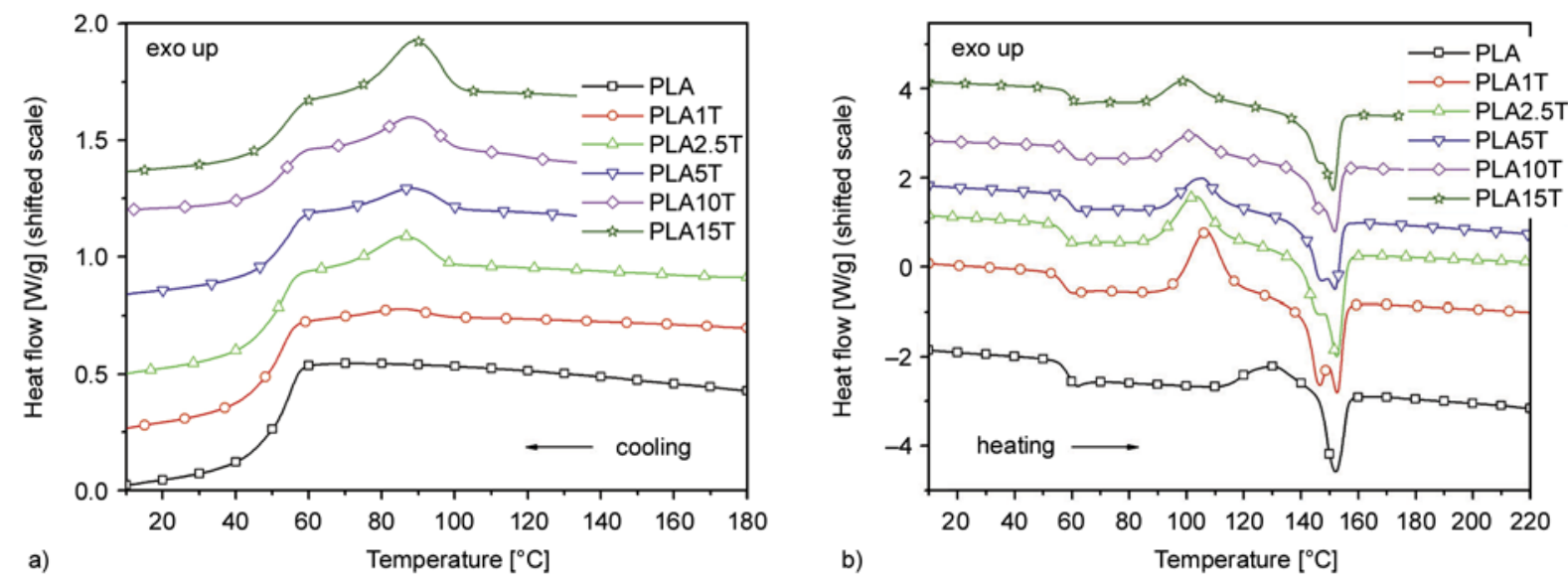

Figure 3. DSC analyses of samples a) cooling $\left.\left(10^{\circ} \mathrm{C} / \min 230-0^{\circ} \mathrm{C}\right) \mathrm{b}\right)$ second heating $\left(10^{\circ} \mathrm{C} / \mathrm{min} 0-230^{\circ} \mathrm{C}\right)$ 
ing cooling, that reduce the chain mobility [3]. This reduction negatively affects cold crystallization process.

Two overlapping melting processes are shown by the composites containing talc $\left(T_{\mathrm{m}}: 147\right.$ and $\left.152^{\circ} \mathrm{C}\right)$ which probably correspond to PLA crystallized respectively on heating and on cooling [11]. The low temperature melting process is reduced to a shoulder increasing talc content which indicates that crystallization on cooling gives crystals with an higher melting temperature. Thus the incorporation of talc leads to an increase of crystallization percentage during cooling and affect the total crystalline percentage obtained with an annealing process.

\subsection{Isothermal crystallization behaviour}

In Figure 4 the heat flow $[\mathrm{W} / g]$ versus $t[\mathrm{~min}]$ at the isothermal temperature $\left(T_{\mathrm{i}}\right)$ of $110^{\circ} \mathrm{C}$ are plotted. Typical crystallization isotherms are obtained for pure PLA and PLA/talc composites. Adding talc the crystallization isotherm curves are shifted to left along the time axis.

In Table 2 are reported all the maximum of the curves $\left(t_{\max }\right)$ obtained at the different $T_{\mathrm{i}}$. By plotting the $T_{\mathrm{i}}$ against the $t_{\max }$ saddle shape curves for PLA composites were obtained (Figure 5). The $t_{\max }$ for PLA/talc composites decrease as the $T_{\mathrm{i}}$ increased, then reach a minimum and start to increase. This minimum is at a $T_{\mathrm{i}}$ of $378 \mathrm{~K}\left(100^{\circ} \mathrm{C}\right)$ for the PLA alone and composites till $5 \mathrm{wt} \%$ of talc, and decrease to $95^{\circ} \mathrm{C}$ for talc concentration higher than $10 \mathrm{wt} \%$.

Table 2. DSC isothermal analysis of PLA and PLA/talc composites

\begin{tabular}{|l|r|r|r|r|r|}
\hline \multirow{2}{*}{ Sample } & \multicolumn{5}{|c|}{$\mathbf{t}_{\mathbf{m a x}}[\mathbf{m i n}]$} \\
\cline { 2 - 6 } & $\mathbf{9 0}^{\circ} \mathbf{C}$ & $\mathbf{9 5}^{\circ} \mathbf{C}$ & $\mathbf{1 0 0}^{\circ} \mathbf{C}$ & $\mathbf{1 0 5}^{\circ} \mathbf{C}$ & $\mathbf{1 1 0}^{\circ} \mathbf{C}$ \\
\hline PLA & 120.0 & 106.2 & 81.5 & 86.2 & 118.0 \\
\hline PLA1T & 8.9 & 4.9 & 4.3 & 4.7 & 6.8 \\
\hline PLA2.5T & 6.9 & 4.6 & 3.0 & 4.3 & 6.2 \\
\hline PLA5T & 4.4 & 2.9 & 2.8 & 3.7 & 4.7 \\
\hline PLA10T & 3.0 & 2.2 & 2.2 & 3.0 & 4.2 \\
\hline PLA15T & 2.8 & 2.0 & 2.0 & 3.0 & 4.0 \\
\hline
\end{tabular}

The minimum $t_{\max }$ for PLA alone is $81 \mathrm{~min}$. At the same temperature the talc reduces this time to 2.0$4.3 \mathrm{~min}$ for PLA/talc composite with various ratios. Thus the crystallization rates of the PLA containing talc were much faster than that of pure PLA. This is obtained at all experimental temperatures indicating that talc extremely increases the PLA crystallization rate. As the talc content in the PLA increased the $t_{\max }$ decreased slightly at all temperatures indicating an increase in PLA crystallization rate.

The Avrami equation [22-24] (Equation (2)) describes how solids transform from one phase to another at constant temperature. It can specifically describe the crystallization kinetics and for these is

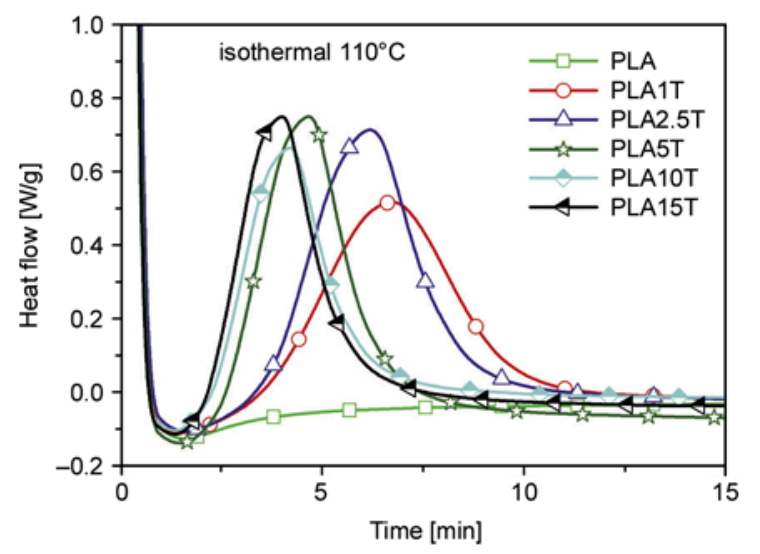

Figure 4. PLA and PLA/talc composites heat flow $[\mathrm{W} / \mathrm{g}]$ versus $t[\mathrm{~min}]$ at the isothermal temperature $\left(T_{\mathrm{i}}\right)$ of $110^{\circ} \mathrm{C}$

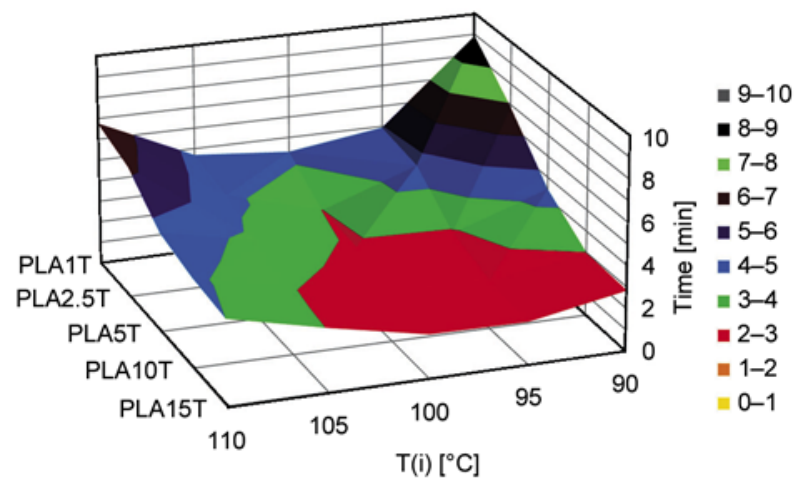

Figure 5. DSC isothermal analysis of PLA/talc composites: $T_{\mathrm{i}}$ versus $t_{\max }$

Table 3. PLA, PLA/talc composites crystallinity percentage after isothermal and after annealing

\begin{tabular}{|l|c|c|c|c|c|c|}
\hline \multirow{2}{*}{\multicolumn{1}{c|}{ Sample }} & \multicolumn{5}{|c|}{$\chi[\mathbf{\%}]$ after isothermal DSC } & \multirow{2}{*}{$\chi[\%]$ after annealing $\mathbf{2} \mathbf{~}$ at $\mathbf{1 0 0}^{\circ} \mathbf{C}$} \\
\cline { 2 - 6 } & $\mathbf{9 0}^{\circ} \mathbf{C}$ & $\mathbf{9 5}^{\circ} \mathbf{C}$ & $\mathbf{1 0 0}^{\circ} \mathbf{C}$ & $\mathbf{1 0 5}^{\circ} \mathbf{C}$ & $\mathbf{1 1 0}^{\circ} \mathbf{C}$ & 24.5 \\
\hline PLA & 7.8 & 21.2 & 27.4 & 28.6 & 17.3 & 26.8 \\
\hline PLA1T & 26.9 & 27.9 & 29.5 & 33.5 & 34.3 & 27.2 \\
\hline PLA2.5T & 27.8 & 27.7 & 32.8 & 31.3 & 34.8 & 29.3 \\
\hline PLA5T & 28.3 & 28.4 & 30.5 & 30.9 & 34.0 & 29.2 \\
\hline PLA10T & 27.8 & 29.6 & 31.6 & 33.0 & 34.6 & 30.1 \\
\hline PLA15T & 26.8 & 29.3 & 31.0 & 31.2 & 36.9 & \\
\hline
\end{tabular}


widely used to describe the isothermal crystallization processes in polymers.

If the following two assumptions are made:

(a) Nucleation rate is either zero (i.e. crystallization occurs due to the growth of pre-existing nuclei) or constant.

(b) Isotropical growth rate is proportional to either time $t$ or $t_{1 / 2}$ (depending whether the devitrification is interface or diffusion controlled) then the classical Kohnogorov-Johnson-Mehl-Avrami (KJMA) equation can be derived to be Equation (2) [25]:

$\chi(t)=\chi_{\infty}\left[1-\exp \left(-k t^{\mathrm{n}}\right)\right]$

where $\left.\chi_{t}\right)$ is the volume crystallinity at time $t ; \chi_{\infty}$ is the volume crystallinity after infinite time (estimated by using $\Delta H_{\infty}$ ); $k$ is the overall kinetic rate constant and $n$ is the Avrami exponent (which depends on the nucleation and growth mechanism of the crystal).

The evolution of the crystallinity with time can be estimated by using the degrees of crystallization $(\alpha)$ as expressed by the ratio of enthalpy determined by DSC using Equation (3):

$\alpha=\frac{\chi(t)}{\chi_{\infty}}=\frac{\Delta H(t)}{\Delta H_{\infty}}$

The value of $\alpha$ at different times $(t)$ is calculated by integrating this curve of enthalpy at selected times and calculating the ratio between this value and the total area of the curve.

Taking the double logarithm of Equation (2) gives Equation (4):

$\ln \left[-\ln \left(1-X_{\mathrm{t}}\right)\right]=\ln (k)+n \ln (t)$

The plot of $\ln \left[-\ln \left(1-X_{\mathrm{t}}\right)\right]$ vs $\ln (t)$ should be linear and the parameters $k$ and $n$ can be determined by curve fitting the experimental data with slope $n$ and intercept $\ln (k)$.

The physical interpretation of the Avrami constants $k$ and $n$ is difficult and open to interpretation. Origi- nally $n$ was held to have an integer value between 1-4 which reflected the nature of the transformation in question. In the derivation above for example the value of 4 can be said to have contributions from three dimensions of growth and one representing a constant nucleation rate. If the nuclei are preformed, and thus present from the beginning, the transformation is only due to the 3-dimensional growth of the nuclei and $n$ has a value of 3 . An interesting condition occurs when nucleation occurs on specific sites (such as grain boundaries or impurities) which rapidly saturate soon after the transformation begins. Initially nucleation may be random and growth unhindered leading to high values for $\mathrm{n}(3$, $4)$. Once the nucleation sites are consumed the formation of new particles will cease. Furthermore if the distribution of nucleation sites is non-random then the growth may be restricted to 1 or 2-dimensions. Site saturation may lead to $n$ values of 1,2 or 3 for surface, edge and point sites respectively.

The $k$ parameter is a temperature-dependent factor which is generally taken in the Arrhenius form (Equation (5)):

$k=k_{0} \cdot \exp \left(-\frac{E}{R T}\right)$

where $E$ is the average activation energy for the overall crystallization process. For isothermal transformation according to Equation (5) we have Equation (6):

$$
\ln (k)=\ln \left(k_{0}\right)-\frac{E}{R T}
$$

The activation energy for crystallization can be determined by plotting $\ln (k)$ vs $1 / T$ and $\ln (k)$ is directly connected to the activation energy. Figure 6 presents plots of $\ln \left[-\ln \left(1-X_{\mathrm{t}}\right)\right]$ vs $\ln (t)$ for the PLA/talc microcomposites at $110^{\circ} \mathrm{C}$. The curves present an early and a nonlinear end part but in the figure only the parts used to do the fitting are

Table 4. Crystallization parameters $\ln (k)$ and $n$ for PLA and PLA/talc microcomposites

\begin{tabular}{|l|c|c|c|c|c|c|c|c|c|c|}
\hline Temperature & \multicolumn{2}{|c|}{$\mathbf{9 0}^{\circ} \mathbf{C}$} & \multicolumn{2}{c|}{$\mathbf{9 5}^{\circ} \mathbf{C}$} & \multicolumn{2}{c|}{$\mathbf{1 0 0}^{\circ} \mathbf{C}$} & \multicolumn{2}{c|}{$\mathbf{1 0 5}^{\circ} \mathbf{C}$} & \multicolumn{2}{|c|}{$\mathbf{1 1 0}^{\circ} \mathbf{C}$} \\
\hline \multicolumn{1}{|c}{ Sample } & $\mathbf{n}$ & $\ln (\mathbf{k})$ & $\mathbf{N}$ & $\mathbf{I n}(\mathbf{k})$ & $\mathbf{n}$ & $\mathbf{I n}(\mathbf{k})$ & $\mathbf{n}$ & $\mathbf{I n}(\mathbf{k})$ & $\mathbf{n}$ & $\operatorname{In}(\mathbf{k})$ \\
\hline PLA & - & - & - & - & 3.06 & -13.06 & - & - & - & - \\
\hline PLA1T & 2.12 & -4.40 & 2.37 & -3.03 & 2.36 & -2.54 & 2.37 & -2.59 & 2.30 & -3.43 \\
\hline PLA2.5T & 2.03 & -3.75 & 2.21 & -2.98 & 2.57 & -2.05 & 2.35 & -2.20 & 2.50 & -3.12 \\
\hline PLA5T & - & - & - & - & 2.31 & -1.61 & 2.27 & -1.93 & 2.39 & -2.57 \\
\hline PLA10T & - & - & - & - & - & - & 2.26 & -1.59 & 2.30 & -2.18 \\
\hline PLA15T & - & - & - & - & - & - & - & - & 2.29 & -2.04 \\
\hline
\end{tabular}


reported. The crystallization parameters $\ln (k)$ and $n$ obtained after fitting are summarized in Table 4. Where there are no data was impossible to do the calculation. For neat PLA there is only one data at $100^{\circ} \mathrm{C}$ (Figure 7).

The $\ln (k)$, and thus the activation energy, decreases increasing the amount of talc. The $\ln (k)$ for pure PLA is -13.06 so the activation energy is higher than PLA/talc composites. For the sample where it was possible to evaluate the $\ln (k)$, it has a minimum value at $100^{\circ} \mathrm{C}$ according to what already reported for $t_{\max }$.

For PLA the Figure 7 shows a nonlinear long early part, as in the other case but longest, and after a linear part fitted with the orange line with $n$ values very near to 3 (Table 4). So the nuclei are preformed and the transformation is only due to the 3dimensional growth of the nuclei. For PLA/talc composites instead at all the $T_{\mathrm{i}}$ under consideration the $n$ factor is $2.3 \pm 0.2$ and remains instead quite constant (except for a little change at $90^{\circ} \mathrm{C}$ ) thus the mechanism of nucleation and growth of the crystal is more similar to a two dimensional growth on a lamellar structure as it can be expected from an epi-

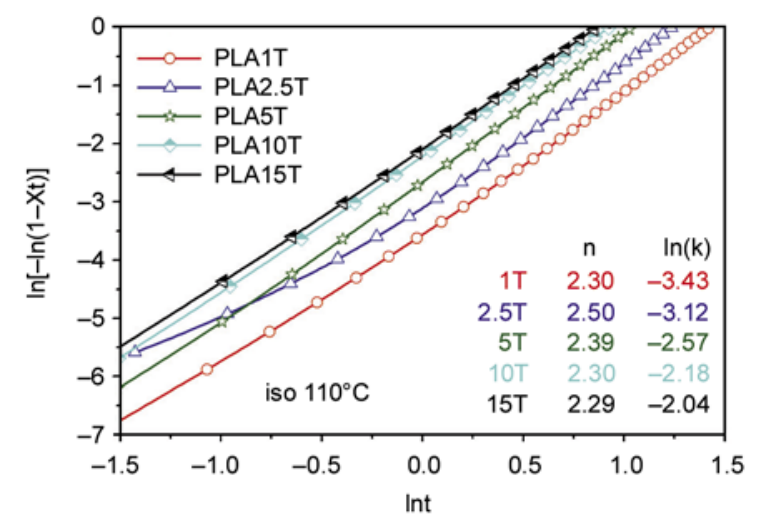

Figure 6. Plots of $\ln \left[-\ln \left(1-X_{\mathrm{t}}\right)\right]$ vs $\ln (t)$ for the microcomposites at $110^{\circ} \mathrm{C}$

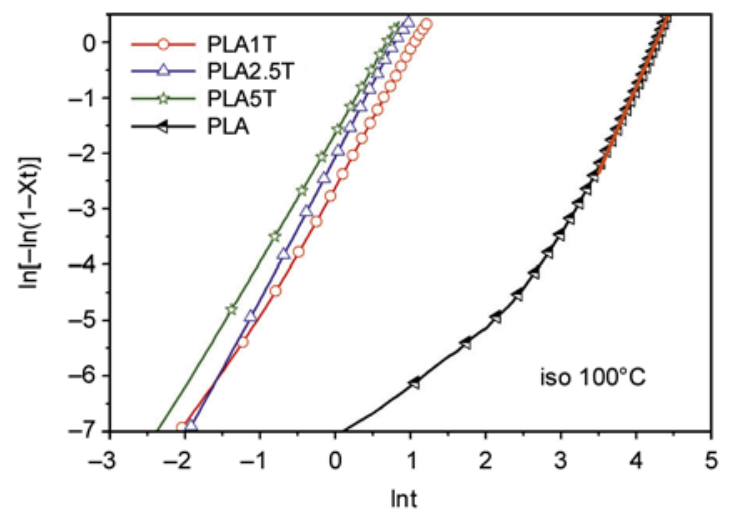

Figure 7. Plots of $\ln \left[-\ln \left(1-X_{\mathrm{t}}\right)\right]$ vs $\ln (t)$ for the PLA at $100^{\circ} \mathrm{C}$ taxial growth mechanism. Thus the micro talc change the mechanism of PLA crystallization strongly reducing the activation energy needed as Kolstad [5] already demonstrated. The mechanism of growth is directly linked to the presence of talc particles that works as nucleating agent with a $2 d$ growth mechanism.

\subsection{Mechanical properties}

In Figure 8 are reported the DMTAs of PLA and talc filled samples. For concentration higher than $5 \mathrm{wt} \%$ the addition of talc into PLA improves modulus as expected. The storage modulus is increased at $30^{\circ} \mathrm{C}$ and this is due to the reinforcing effect of talc. Under $5 \mathrm{wt} \%$ of talc content no relevant differences are highlighted thus the increase of crystalline percentage seems not to affect the storage modulus of PLA.

Considerable improvements of rigidity were instead observed at higher temperatures upon addition of talc for all loadings. In Figures 8 and 9 all the data obtained from DMTA tests of all samples at 30 and $85^{\circ} \mathrm{C}$ and the peak temperatures of $\tan \delta$ are summarized. Because of the low modulus the test of PLA must be stopped at about $80^{\circ} \mathrm{C}$ instead also at low loading (i.e. $1 \mathrm{wt} \%$ ), where the addition of talc into PLA that leads to no change in the storage modulus at $30^{\circ} \mathrm{C}$, the composites show an increase of modulus at higher temperature (Figure 8): the $1 \mathrm{wt} \%$ of talc is enough to allow the PLA to reach the test end $\left(100^{\circ} \mathrm{C}\right)$.

At high temperature the addition of 5, 10 and $15 \mathrm{wt} \%$ of talc leads to increases of storage modulus respectively of 260, 430 and $600 \mathrm{MPa}$ thus the increases of the storage modulus are directly correlated to talc percentage. These increases at high temperature could be associated to the reinforcement effect of particles in the polymer matrix or to the crystallization induced by talc on the PLA.

To better understand the role on reinforcement of the PLA crystals and of the filler, DMTA were repeated on samples annealed for 2 hours at $100^{\circ} \mathrm{C}$ to permit the maximum crystallization. After the annealing the samples were tested on DSC to verify the reached crystallinity. The results are reported in Figure 9 and Table 3. The crystallinity after annealing (Table 3 ) is $25 \%$ for neat PLA and increase with the talc content to $30 \%$ as expected from the previous DSC isothermal data. The total crystallinity of 

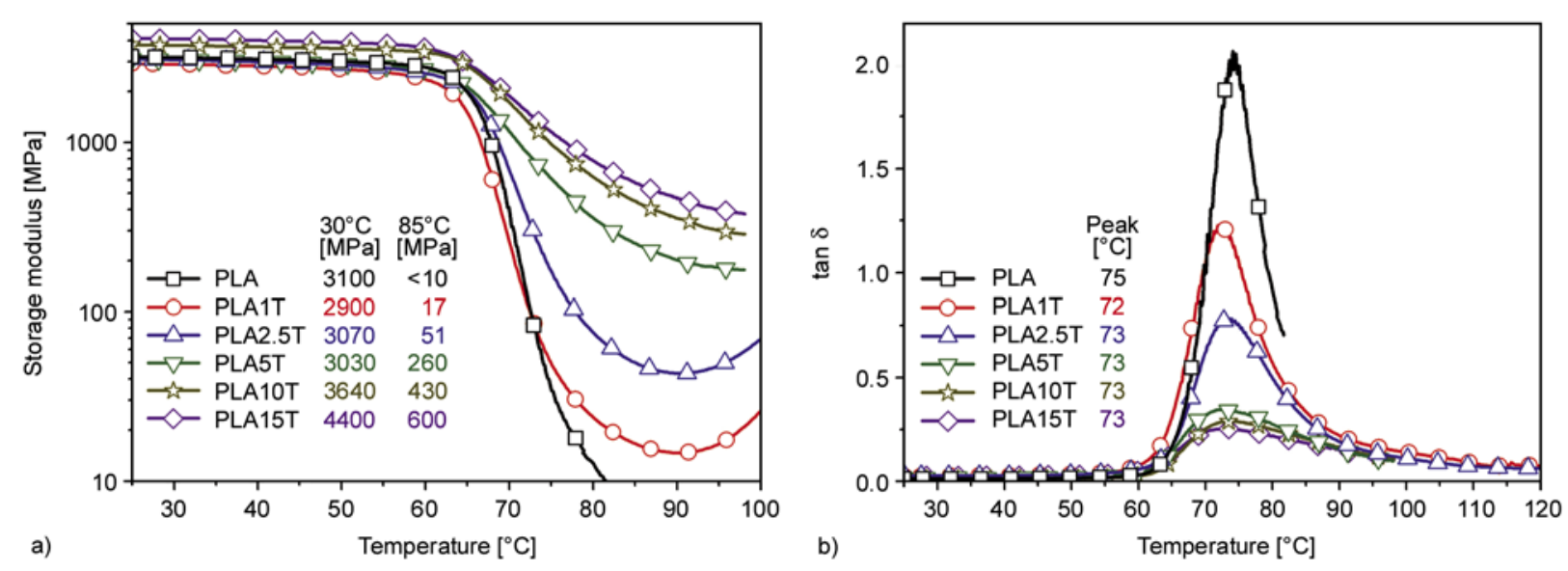

Figure 8. DMTA of PLA and PLA/talc composites. Storage modulus (a) and $\tan \delta$ (b)
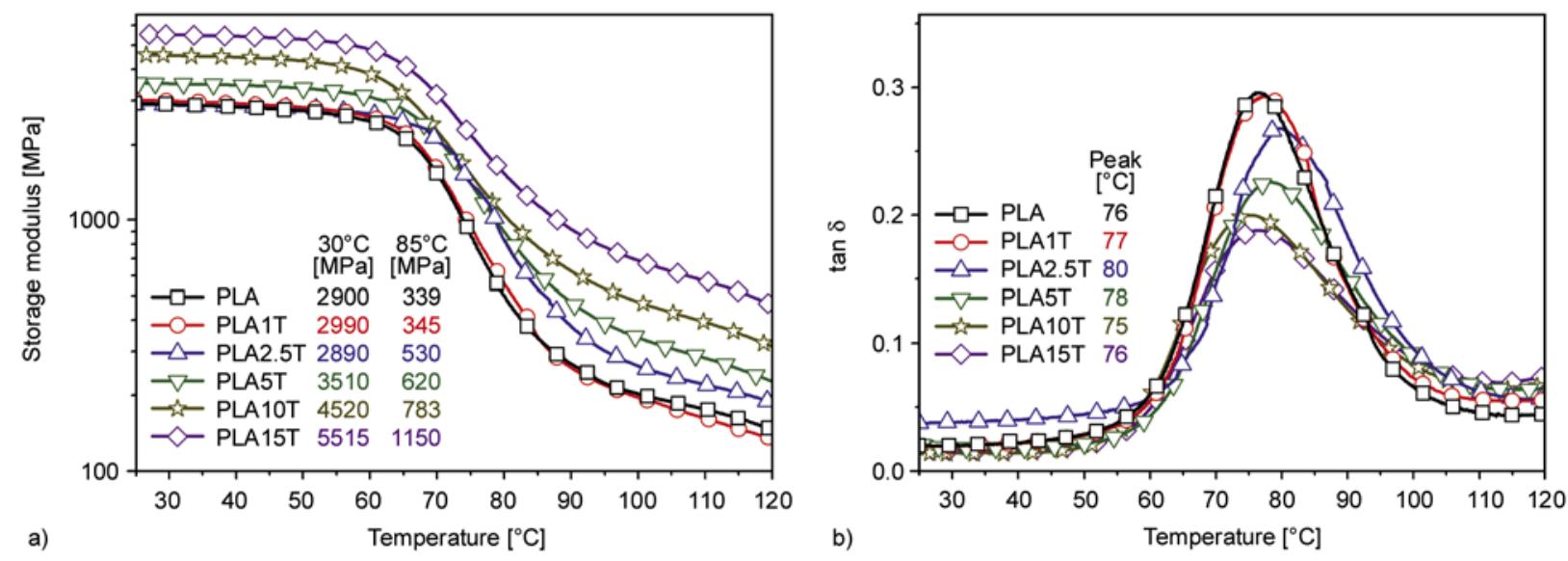

Figure 9. DMTA of PLA and PLA/talc composites after annealing $\left(2 \mathrm{~h}\right.$ at $\left.100^{\circ} \mathrm{C}\right)$. Storage modulus (a) and $\tan \delta(\mathrm{b})$

the annealed samples is different from the corresponding samples measured with DSC. The differences are due to the thermal history of the samples: the DSC samples were quenched while the samples for mechanical analyses were heated from room temperature to isothermal condition for annealing. At $30^{\circ} \mathrm{C}$ the storage modulus is not influenced by talc and by the crystallinity level under the $2.5 \mathrm{wt} \%$ of talc content thus the main reinforcing effect in this case is due to the glassy state of PLA. Above this content ( $5 \mathrm{wt} \%$ and more) there is a linear increase of the storage modulus directly correlated to the talc addition. With the samples annealed the modulus increases faster with talc content than with un-annealed samples. This behaviour suggests that there is a synergistic effect between talc filler and crystallinity. At $85^{\circ} \mathrm{C}$ the storage modulus of pure PLA annealed is about $340 \mathrm{MPa}$ and the sample reach the end of the test now fixed at $120^{\circ} \mathrm{C}$. Thus, over the $T_{\mathrm{g}}$, the crystallinity highly affects the thermo-mechanical properties of PLA. For annealed samples at high temperature the storage modulus directly increase with talc content and it seems due to the linear addition of talc effect and crystals presence.

Finally there is a small increase in the glass transition temperature (peak of $\tan \delta$ ) of the different samples after annealing (Figure 8, Figure 9). Probably during annealing the low molecular weight molecules, that are the molecules with the higher mobility, are included in the growing crystals. The low molecular weight molecules are the same that act as plasticizing agents for PLA amorphous part thus the result is an increase of the glass transition temperature.

\section{Conclusions}

To allow PLA utilization in engineering applications addition of selected fillers by melt-blending represents a good methodology for improving its performance. PLA based-composites obtained by addition of talc present considerable improvements 
in the thermal and mechanical properties of PLA thus they are potentially interesting for technical applications. The incorporation of talc particles significantly accelerates the crystallization process of the PLA matrix.

The crystallization behaviour of PLA/talc composites during cooling is mainly influenced by the composition and the crystallization temperatures. The talc in PLA/talc composites can effectively increase the crystallization rate of PLA, even at a content of $1 \mathrm{wt} \%$. The crystallization rate increased slightly as the talc content in the composite increased. The maximum speed of crystallization is reached with the annealing temperature of $100^{\circ} \mathrm{C}$ for the PLA and a lower $\left(95^{\circ} \mathrm{C}\right)$ for talc high content samples.

The kinetics of crystallization obtained using the Avrami equation shows that PLA/talc microcomposites has a different growth kinetics that is more similar to a two dimensional growth on a lamellar structure such as an epitaxial growth. Moreover micro talc strongly reduces the activation energy.

At high temperature the modulus increase is due to a synergistic effect between crystals and filler, thus in order to have materials with good performances both the presence of a filler and PLA crystals are necessary.

\section{References}

[1] Shen L., Haufe J., Patel M. K.: Product overview and market projection of emerging biobased plastics: PRO-BIP 2009. Final Report, Utrecht University (2009).

[2] Lim L-T., Auras R., Rubino M.: Processing technologies for poly(lactic acid). Progress in Polymer Science, 33, 820-852 (2008).

DOI: $10.1016 /$ j.progpolymsci.2008.05.004

[3] Li H., Huneault M. A.: Effect of nucleation and plasticization on the crystallization of poly(lactic acid). Polymer, 48, 6855-6866 (2007). DOI: $10.1016 /$ j.polymer.2007.09.020

[4] Bigg D. M.: Controlling the performance and rate of degradation of polylactide copolymers. in 'Annual Technical Conference - ANTEC 2003 Conference Proceedings, Nashville, USA', Vol 3, 2816-2822 (2003).

[5] Kolstad J. J.: Crystallization kinetics of poly(L-lactideco-meso-lactide). Journal of Applied Polymer Science, 62, 1079-1091 (1996).

DOI: $10.1002 /($ SICI)1097-4628(19961114)62:7<1079 ::AID-APP14>3.0.CO;2-1
[6] Nijenhuis A. J., Grijpma D. W., Pennings A. J.: Highly crystalline as-polymerized poly(L-lactide). Polymer Bulletin, 26, 71-77 (1991).

DOI: $10.1007 / \mathrm{BF} 00299350$

[7] Kalb B., Pennings A. J.: General crystallization behaviour of poly(L-lactic acid). Polymer, 21, 607-612 (1980)

DOI: 10.1016/0032-3861(80)90315-8

[8] Cohn D., Younes, H., Marom G.: Amorphous and crystalline morphologies in glycolic acid and lactic acid polymers. Polymer, 28, 2018-2022 (1987). DOI: 10.1016/0032-3861(87)90035-8

[9] Migliaresi C., de Lollis A., Fambri L., Cohn D.: The effect of thermal history on the crystallinity of different molecular weight PLLA biodegradable polymers. Clinical Materials, 8, 111-118 (1991). DOI: 10.1016/0267-6605(91)90018-B

[10] Urbanovici E., Schneider H. A., Brizzolara D., Cantow H. J.: Isothermal melt crystallization kinetics of poly(Llactic acid). Journal of Thermal Analysis and Calorimetry, 47, 931-939 (1996).

DOI: $10.1007 / \mathrm{BF} 01979440$

[11] Tábi T., Sajó I. E., Szabó F., Luyt A. S., Kovács J. G.: Crystalline structure of annealed polylactic acid and its relation to processing. Express Polymer Letters, 4, 659-668 (2010).

DOI: $10.3144 /$ expresspolymlett.2010.80

[12] Kishore K., Vasanthakumari R., Pennings A. J.: Isothermal melting behavior of poly(L-lactic acid). Journal of Polymer Science: Polymer Physics Edition, 22, 537542 (1984).

DOI: 10.1002/pol.1984.180220401

[13] Vasanthakumari R., Pennings A. J.: Crystallization kinetics of poly(L-lactic acid). Polymer, 24, 175-178 (1983).

DOI: $10.1016 / 0032-3861(83) 90129-5$

[14] Tsuji H., Ikada Y.: Properties and morphologies of poly(L-lactide): 1. Annealing condition effects on properties and morphologies of poly(L-lactide). Polymer, 36, 2709-2716 (1995). DOI: 10.1016/0032-3861(95)93647-5

[15] Migliaresi C., Cohn D., de Lollis A., Fambri L.: Dynamic mechanical and calorimetric analysis of compression-molded PLLA of different molecular weights: Effect of thermal treatments. Journal of Applied Polymer Science, 43, 83-95 (1991). DOI: $10.1002 / a p p .1991 .070430109$

[16] Haubruge H. G., Daussin R., Jonas A. M., Legras R., Wittmann J. C., Lotz B.: Epitaxial nucleation of poly (ethylene terephthalate) by talc: Structure at the lattice and lamellar scales. Macromolecules, 36, 4452-4456 (2003).

DOI: $10.1021 / \mathrm{ma} 0341723$ 
[17] Ke T., Sun X.: Melting behavior and crystallization kinetics of starch and poly(lactic acid) composites. Journal of Applied Polymer Science, 89, 1203-1210 (2003).

DOI: $10.1002 / a p p .12162$

[18] Fukada E.: Piezoelectricity of biopolymers. Biorheology, 32, 593-609 (1995).

DOI: 10.1016/0006-355X(95)00039-C

[19] Turner J. F., Riga A., O’Connor A., Zhang J., Collis J.: Characterization of drawn and undrawn poly-L-lactide films by differential scanning calorimetry. Journal of Thermal Analysis and Calorimetry, 75, 257-268 (2004). DOI: 10.1023/B:JTAN.0000017347.08469.b1

[20] Rayner J. H., Brown G.: The crystal structure of talc. Clays and Clay Minerals, 21, 103-114 (1973). DOI: $10.1346 / C C M N .1973 .0210206$

[21] Xiao H. W., Li P., Ren X., Jiang T., Yeh J-T.: Isothermal crystallization kinetics and crystal structure of poly(lactic acid): Effect of triphenyl phosphate and talc. Journal of Applied Polymer Science, 118, 35583569 (2010).

DOI: $10.1002 / \mathrm{app} .32728$
[22] Avrami M.: Kinetics of phase change. I. General theory. Journal of Chemical Physics, 7, 1103-1112 (1939). DOI: $10.1063 / 1.1750380$

[23] Avrami M.: Kinetics of phase change. II. Transformation-time relations for random distribution of nuclei. Journal of Chemical Physics, 8, 212-224 (1940). DOI: $10.1063 / 1.1750631$

[24] Avrami M.: Granulation, phase change, and microstructure kinetics of phase change. III. Journal of Chemical Physics, 9, 177-184 (1941). DOI: $10.1063 / 1.1750872$

[25] Sun N. X., Liu X. D., Lu K.: An explanation to the anomalous avrami exponent. Scripta Materialia, 34, 1201-1207 (1996).

DOI: $\underline{10.1016 / 1359-6462(95) 00657-5}$ 